\title{
Soft tissue coverage of lower extremity defects: pearls and pitfalls in the chronic wound population
}

\author{
Romina Deldar ${ }^{1,2}$, Chamilka Merle ${ }^{2}$, Christopher E. Attinger ${ }^{1}$, Karen K. Evans ${ }^{1}$ \\ 'Department of Plastic and Reconstructive Surgery, MedStar Georgetown University Hospital, Washington, DC 20007, USA. \\ 2Department of General Surgery, MedStar Georgetown University Hospital, Washington, DC 20007, USA. \\ Correspondence to: Dr. Karen K. Evans, Department of Plastic and Reconstructive Surgery, MedStar Georgetown University \\ Hospital, 3800 Reservoir Road, NW, Washington, DC 20007, USA. E-mail: karen.k.evans@medstar.net, \\ prsgeorgetownresearch@gmail.com
}

How to cite this article: Deldar R, Merle C, Attinger CE, Evans KK. Soft tissue coverage of lower extremity defects: pearls and pitfalls in the chronic wound population. Plast Aesthet Res 2022;9:13. https://dx.doi.org/10.20517/2347-9264.2021.100

Received: 7 Sep 2021 First Decision: 11 Oct 2021 Revised: 19 Oct 2021 Accepted: 29 Dec 2021 Published: 8 Feb 2022

Academic Editors: Matthew L Iorio, Marten Basta Copy Editor: Xi-Jun Chen Production Editor: Xi-Jun Chen

\begin{abstract}
The incidence of chronic lower extremity (LE) wounds continues to increase. Lower limb amputations are associated with increased cardiovascular exertion, further decline in functional ability, and higher mortality rates. As such, there has been a shift towards limb salvage modalities. These include local debridement with advanced wound care, revascularization, bony reconstruction, and soft tissue reconstruction. Perioperative planning for soft tissue reconstruction requires careful consideration of several factors, including patient comorbidities, wound size and location, exposed underlying structures, and in the case of possible free flap, patency of donor and recipient vessels. This article reviews the perioperative factors that should be considered in preparation for successful soft tissue reconstruction of the LE.
\end{abstract}

Keywords: Free tissue transfer, chronic wounds, lower extremity, reconstruction

\section{INTRODUCTION}

Chronic wounds of the lower extremity (LE) can be defined as wounds that fail to heal within three months of onset. LE wounds are a relatively common condition, affecting $1 \%$ of the adult population and $3.6 \%$ of people older than age $65^{[1-3]}$. This incidence continues to rise as a result of an aging population and increased atherosclerotic risk factors such as smoking, obesity, and diabetes mellitus $(\mathrm{DM})^{[1]}$. Diabetic foot ulcers 
(DFU) can cause a devastating impact on patient quality of life in terms of chronic pain, infection, decreased ambulation, social distress, and ultimately survival ${ }^{[4]}$.

LE wound healing complications are a major concern in diabetic patients, with a lifetime incidence of DFU as high as $25 \%{ }^{[5,6]}$. Nearly $75 \%$ of all lower limb amputations are performed in diabetic patients ${ }^{[7]}$. Following major LE amputation, 5-year mortality rates can reach 56.6\%, which are higher than breast, colon, or prostate cancer $^{[8]}$. This is likely due to increased cardiovascular exertion, further decline in functional ability, and exacerbation of existing comorbidities ${ }^{[0]}$. Moreover, major LE amputation increases the risk of contralateral amputation by up to $50 \%$ within two years ${ }^{[10-12]}$.

Thus, recent advancements in the treatment of chronic LE wounds have focused on limb salvage modalities. These include local debridement, advanced wound care, revascularization, bony reconstruction, and soft tissue reconstruction. Planning for soft tissue reconstruction requires careful consideration of several factors, including patient comorbidities, size and location of the wound, exposed underlying structures, and in the case of the possible free flap, patency of donor and recipient vessels. This article aims to review the perioperative considerations, and local and free flap options that are essential to provide successful soft tissue coverage in the chronic LE wound population.

\section{DISCUSSION}

\section{Preoperative optimization}

Planning for soft tissue reconstruction requires optimization of patient comorbidities and wound bed preparation. This should entail a multidisciplinary collaboration amongst providers from different surgical and medical specialties. These include but are not limited to plastic surgery, orthopedic surgery, vascular surgery, podiatric surgery, internal medicine, endocrinology, cardiology, and hematology.

From a medical perspective, a thorough history detailing all pre-existing medical conditions should be obtained. In diabetic patients, tight glycemic control is essential. Patients with perioperative blood glucose levels greater than $200 \mathrm{mg} / \mathrm{dL}$ or hemoglobin A1c > 6.5\% are more than three times likely to experience wound dehiscence ${ }^{[13,14]}$. Close partnerships with endocrinologists and diabetes educators are important for long-term blood glucose maintenance. Our team's goal is to maintain blood glucose levels perioperatively less than $200 \mathrm{mg} / \mathrm{dL}$. The ideal perioperative HgbA1c is less than 7; however, if a patient's HgbA1c is greater than 7 , this is not a contraindication to free tissue transfer (FTT) because it may be falsely elevated perioperatively secondary to hyperglycemia from acute infection. Nutrition labs, including albumin and prealbumin, should also be obtained preoperatively as malnutrition has negative effects on the wound healing process ${ }^{[15,16]}$. Hypoalbuminemia results in delayed tissue healing, reduced collagen synthesis, and a decrease in plasma colloid osmotic pressure, thereby causing tissue edema and leakage of interstitial fluid, which mediates bacterial propagation into wounds ${ }^{[15,17]}$. Our institution previously found that in patients undergoing FTT, a preoperative albumin level less than $2.7 \mathrm{~g} / \mathrm{dL}$ was associated with decreased flap healing outcomes $^{[18]}$. In general, a low prealbumin level $(<10 \mathrm{mg} / \mathrm{dL})$ is associated with decreased free flap survival rate $^{[19]}$.

Smoking cessation can reduce the risk of impaired wound healing, infection, partial flap loss, and need for revision surgery ${ }^{[20]}$. We encourage patients to refrain from tobacco use for at least four to eight weeks prior to reconstructive surgery; however, this may not be possible if the wound requires free flap immediately. Smoking is not a contraindication for free flap surgery in this population, but the patient must be educated that delayed healing is likely. In our practice, we also screen patients for inherited or acquired hypercoagulable traits that may predispose them to thrombosis. A hypercoagulable workup is a subject of 
debate among microsurgeons and is not routinely performed in many centers. Underlying hypercoagulability can lead to microvascular thrombosis and subsequent flap failure with high rates of nonsalvageability ${ }^{[21-23]}$. In 2015, our institution implemented a risk-stratified algorithm for perioperative anticoagulation, whereby administration of heparin (subcutaneous or intravenous) following FTT is determined by the presence of thrombophilic risk factors for microvascular thrombosis ${ }^{[22]}$. Prior to undergoing FTT, high-risk patients undergo a hypercoagulable workup, including a thrombophilia panel and thorough history taking, to assess for any personal or family history of thromboembolism. Table 1 outlines the components of a thorough thrombophilia screening panel. Our group previously reported that $61 \%$ of patients undergoing FTT to LE reconstruction had at least one hypercoagulable trait; the most common traits were plasminogen activator inhibitor-1 4G/5G variant and methylenetetrahydrofolate reductase (MTHFR) A1298C and C677T polymorphisms ${ }^{[23]}$. In addition, in patients with documented thrombophilia, the use of a weight-based heparin drip titrated to a goal partial thromboplastin (PTT) of 5070 s decreased flap failure from $19 \%$ to $3 \%{ }^{[22]}$.

\section{Wound bed preparation}

From a surgical perspective, aggressive debridement and wound bed preparation is the first step in wound management. Serial excisional debridements are required until all infected or devitalized tissue and biofilm have been removed ${ }^{[2,25]}$ [Figure 1]. Wide excision to a healthy wound bed is necessary, as there is up to a six-fold increase in amputation if the wound is closed with positive post-debridement cultures among diabetic patients undergoing LE FTT ${ }^{[26]}$. Poor host defenses, high glucose levels, and periwound blood supply likely amplify the effect of residual bacterial colonization on the ultimate reconstructive outcome ${ }^{[27]}$.

Aerobic and anaerobic cultures are obtained deep to the wound surface before and after each debridement. Infectious disease (ID) specialists are consulted to assist in culture-driven antibiotic therapy. Antibiotics should be continued until cultures are negative; at this time, a patient is deemed ready for soft tissue reconstruction from an ID standpoint.

In addition, in our operating rooms, we use a two-table setup of sterile instruments in the operating room, including glove exchange to reduce instrument cross-contamination during excisional debridement and coverage or closure of infected wounds ${ }^{[28]}$. Using a two-table setup, we found a $78 \%$ absolute risk reduction in cross-contamination ${ }^{[28]}$. Therefore, it is critical to avoid recontamination of a surgically debrided wound as reinfection could lead to devastating sequelae.

\section{Biomechanical principles}

Prior to wound closure, patients should undergo biomechanical examination and gait analysis with podiatric and/or orthopedic surgery to identify mechanical factors that may contribute to wound development or recurrence if not addressed. Any foot or ankle deformity, in conjunction with diabetic neuropathy, can increase the risk of DFU development ${ }^{[2,30]}$. Peripheral neuropathy is characterized by loss of protective sensation and proprioception, muscle weakness, and imbalance; all of these can contribute to increased plantar pressures during gait ${ }^{[31-34]}$. Contracture of the Achilles tendon causes limited joint mobility at the ankle, defined as equinus deformity. This has been implicated as a major factor in the development of midfoot Charcot collapse and plantar ulcer formation ${ }^{[34-37]}$. We routinely address equinus gait with Achilles tendon lengthening, which has been shown to reduce DFU recurrence by up to $95 \%$ in this population ${ }^{[38]}$. Biomechanical foot and ankle stabilization may require surgical intervention, including tendon transfers, minor bony amputation, or Charcot realignment and stabilization. Calcaneal gait, characterized by increased ankle dorsiflexion during midstance, is another manifestation of Charcot foot ${ }^{[39]}$. Calcaneal ulcers are difficult to heal and usually require surgery to correct the deformity causing the ulcer ${ }^{[40]}$. 
Table 1. Thrombophilia screening panel

Basic labs

- $\mathrm{CBC}$

-PT/INR

-PTT

\section{Hypercoagulable tests}

- Factor V Leiden G1691A genotype

- Prothrombin G20210A genotype

- Homocysteine level

- Factor VIII level

- Antiphospholipid antibody testing

- Antithrombin III activity

- Protein C activity

- Protein S activity

- MTHFR polymorphisms (A1298C and C677T)

- PAI-1 4G/5G QST

CBC: Complete blood count; PT/INR: prothrombin time/international normalized ratio; PTT: partial thromboplastin time; MTHFR: methylenetetrahydrofolate reductase; PAI-1: plasminogen activator inhibitor 1; QST: quantitative sensory testing.
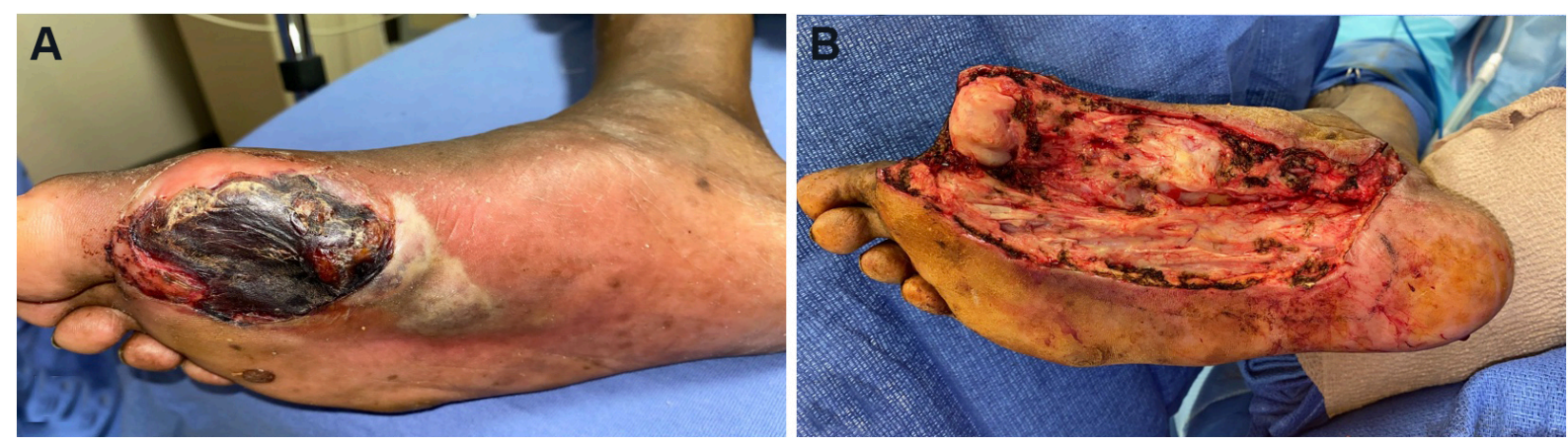

Figure 1. Wound bed preparation. (A) Pre-debridement photo: poorly-controlled diabetic male with systemic signs of sepsis and necrotizing soft tissue infection. Patient was taken urgently to the operating room for debridement. (B) Post-debridement photo: all necrotic debris was removed. The purulence tracked into the tarsal tunnel, which required incision and drainage. Patient underwent serial debridements until negative cultures, and ultimately required free tissue transfer for limb salvage.

\section{Vascular workup}

The prevalence of DM and peripheral vascular disease (PVD) is high in patients that suffer from chronic LE wounds $s^{[1-43]}$. Decreased perfusion in the LE results in impaired wound healing, which can lead to repeat ulceration, infection, and necrosis ${ }^{[41,44]}$. The same pathology that impairs perfusion needed for wound healing also creates barriers for successful FTT, as hypoperfusion is the primary predictor of flap failure ${ }^{[41,45]}$. Venous reflux causing congestion and delayed venous thrombosis is another leading cause of flap failure ${ }^{[46,47]}$. Therefore, it is imperative that vascular studies to assess the arterial and venous systems are obtained prior to free flap planning to mitigate any inflow or outflow issues that could arise.

In our practice, preoperative vascular workup includes an angiogram and venous duplex ultrasound. Angiogram is performed to evaluate the arterial system of the affected limb as well as to optimize recipient vessel selection for the free flap ${ }^{[41]}$. This allows for the identification of any diseased vessels as well as a direct intervention using balloon angioplasty or stenting. Angiogram is preferred over computed tomography angiography because the dye load is much less, and thus, there is a lower risk for acute kidney injury. Janhoferet al. ${ }^{[4]}$ evaluated routine preoperative angiograms completed on patients undergoing LE FTT and found abnormalities in $67.8 \%$ of patients, which included vessel stenosis, occlusion, and non-visualization; $27.5 \%$ of patients required some form of vascular intervention, and of these patients, $15.3 \%$ were newly diagnosed with PVD. Venous duplex can help identify venous insufficiency and pre-existing deep vein 
thrombosis (DVT). The ideal recipient vein can be determined preoperatively based on reflux studies and high venous pressure. If high venous reflux is detected, a different recipient venous system with less disease burden can be chosen ${ }^{[46]}$. Our group has previously reported that venous insufficiency (defined as $<0.5 \mathrm{~s}$ of reflux) was detected in $39 \%$ of patients, and DVT was found in $6.78 \%$ of patients undergoing FTT $^{[46]}$. Identification of both arterial and venous disease prior to FTT allows for optimization of recipient arterial and venous selection to yield free flap success.

\section{Angiosomes of the foot and ankle}

Taylor and Palmer ${ }^{[48]}$ introduced the angiosome concept, separating the body into distinct threedimensional blocks of tissue and overlying skin fed by "source" arteries. The senior authors (Attinger CE and Evans $\mathrm{KK}$ ) described six angiosomes of the foot and ankle that originate from three main arteries ${ }^{[49]}$ [Figure 2]. Blood flow to the foot and ankle is redundant because of the multiple arterial-arterial connections between the three main arteries ${ }^{[49]}$.

Application of the angiosome theory is important in reconstructive success of the foot and ankle ${ }^{[50]}$. Knowledge of the vascular anatomy of the foot and ankle can guide the effective revascularization of occluded arteries ${ }^{[4,51]}$. Incisions in the foot and ankle should be made between angiosome boundaries to limit perfusion compromise. Detailed descriptions of the vascular anatomy and angiosomes of the lower leg, foot, and ankle have been explained elsewhere ${ }^{[0,52-54]}$.

\section{Local flaps for LE reconstruction}

In general, flap coverage is the reconstructive choice for wounds with exposed tendon, joint, or bone $e^{[55]}$. The primary goal of the lower leg, foot, and ankle reconstruction is to preserve function, centered on ambulation. Local flaps can improve blood flow to the defect and provide a surface for subsequent skin grafting $^{[50]}$. Historically, the gastrocnemius and soleus muscle flaps have provided dependable coverage of lower limb defects ${ }^{[6,57]}$. The gastrocnemius local flap with skin graft has been widely used for reconstruction of knee and proximal leg defects [Figure 3]. The soleus muscle flap can provide reliable soft-tissue coverage of middle and lower leg defects ${ }^{[57,58]}$. In select patients, the medial sural artery perforator (MSAP) flap is useful as a pedicled or free flap to cover knee or leg defects. It is based on perforators from the medial sural artery, which are dissected through the gastrocnemius muscle ${ }^{[59]}[$ Figure 4].

Fasciocutaneous flaps can also be used for coverage of the knee, leg, and posterior heel. The reverse sural artery flap offers coverage of distal leg and heel defects when microsurgery is not feasible; however, venous congestion and distal flap loss are common complications ${ }^{[60]}$ [Figure 5]. Perforator-based local flaps, such as propeller or keystone flaps, have expanded the repertoire for lower limb reconstruction. Figure 6 depicts a saphenous artery perforator-based rotation advancement flap. Moreover, the perforator-plus flap, a modification of the classic perforator-based fasciocutaneous flap, offers dual blood supply to the flap from the dissected perforator plus the retained cutaneous base ${ }^{[61]}$. By keeping the base of the flap attached, the subdermal plexus augments arterial inflow, improves venous outflow, and shortens the arc of flap rotation $^{[62]}$. AlMugaren et al. ${ }^{[56]}$ recently published an algorithm for the reconstruction of LE defects. Disadvantages of local flaps include limited bulk and reach ${ }^{[5]}$.

\section{Local flaps for foot reconstruction}

Local muscle flaps can be used for coverage of small foot defects $(3 \mathrm{~cm} \times 6 \mathrm{~cm}$ or less) that are within reach of the local flap ${ }^{[55]}$. At our center, we primarily use three intrinsic foot muscles for coverage of diabetic foot wounds: (1) abductor hallucis (AH); (2) abductor digiti minimi (ADM); and (3) flexor digitorum brevis (FDB) [Figures 7-9]. To harvest each of these flaps, the incisions are made along the border of adjacent 

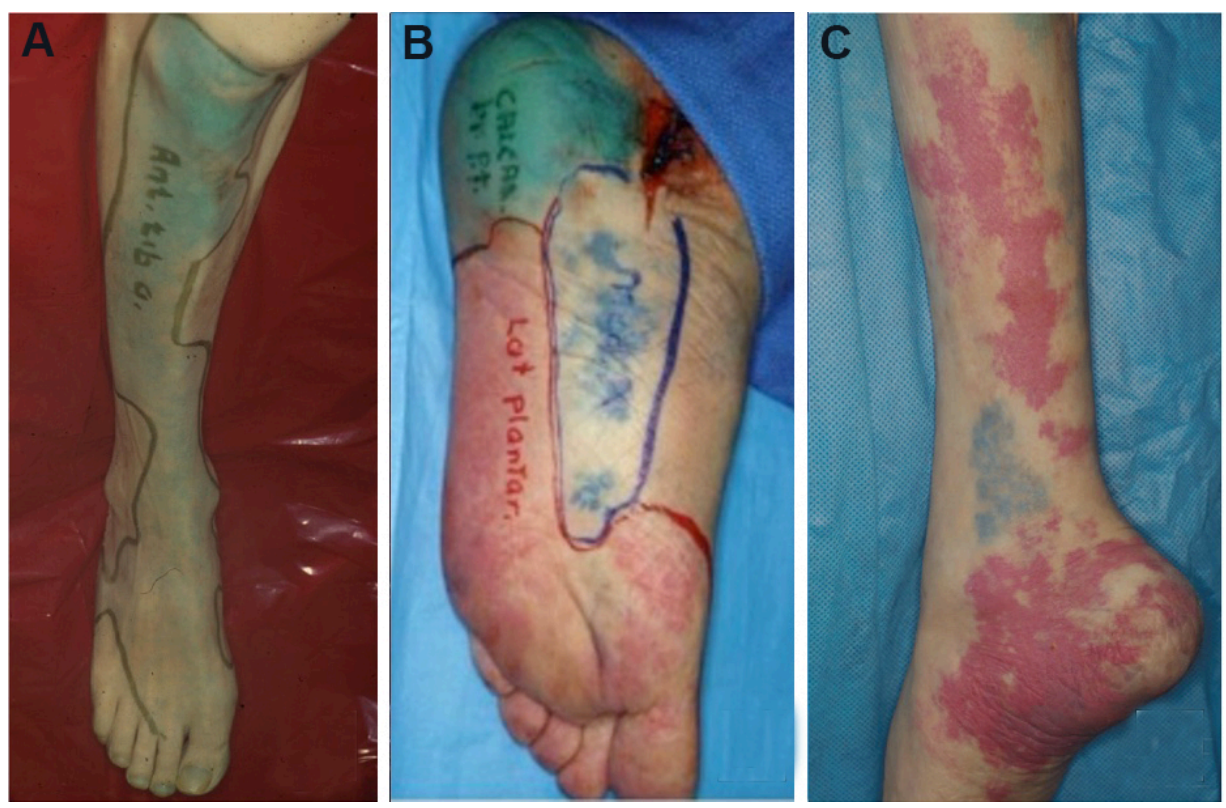

Figure 2. Angiosomes of the foot and ankle. (A) Anterior tibial angiosome: supplies the anterior ankle and continues as the dorsalis pedis artery to supply the dorsal foot. (B) Posterior tibial angiosome: supplies the plantar foot via 3 branches: calcaneal, medial plantar, and lateral plantar arteries. (C) Peroneal angiosome supplies the anterolateral portion of the ankle and hindfoot via 2 branches: lateral calcaneal and anterior perforator arteries. Figure adapted with permission from Ref. ${ }^{[49]}$.

angiosomes. Thus, the soft tissue on either side of the donor site incision should be well-vascularized to allow the wound edges at the donor site to heal primarily ${ }^{[55]}$. We use the AH flap to cover wounds on the medial midfoot, ankle, and heel, and the ADM flap to cover lateral ankle and foot ${ }^{[55]}$. The FDB flap can be used for calcaneal defects. Limitations of local pedicled flaps include limited bulk and reach. Preoperative planning should ensure that the rotated muscle will sufficiently definitively cover exposed joint, tendon, or bone; any uncovered granulating tissue can be covered by skin grafts or biologic wound matrices ${ }^{[55]}$.

\section{Free flaps for LE reconstruction}

Because of continued advances in microsurgery, FTT has become a reliable reconstructive solution, with high rates of flap success and limb salvage ${ }^{[63,64]}$. Large wounds in the distal third of the leg, ankle, and foot often require free tissue reconstruction ${ }^{[65]}$. There are three main considerations to guide the choice of optimal free flap for LE defect: (1) flap composition; (2) functional and aesthetic outcomes; and (3) donor site morbidity. There are four flap compositions that can be used for most LE reconstructions: fasciocutaneous, muscle only, musculocutaneous, or chimeric ${ }^{[66]}$. Hollenbeck et al ${ }^{[67]}$ described the subunit principle of the foot, which provides a framework to determine which free flap will lend the best functional and aesthetic outcome in a given area of the foot or ankle.

At our institution, we most commonly use flaps from the descending branch of the lateral circumflex artery [i.e., the anterolateral thigh (ALT) or vastus lateralis (VL) flaps] for LE reconstruction ${ }^{[50]}$ [Figure 10]. These workhorse flaps for LE reconstruction offer low donor site morbidity and long pedicles that are large in diameter ${ }^{[50,68]}$. However, the bulk offered by these flaps is not ideal for the dorsal surface of the foot, which requires coverage with thinner tissue so the foot can still fit into a shoe. In these cases, flaps with thinner paddles are preferred: the radial forearm flap, MSAP flap, or superior circumflex iliac artery perforator (SCIP) flap are reasonable options ${ }^{[50,59]}$ [Figure 11]. Limitations of the SCIP flap include a short, small caliber pedicle, while the MSAP flap requires tedious muscle dissection and susceptibility to vein damage given the 


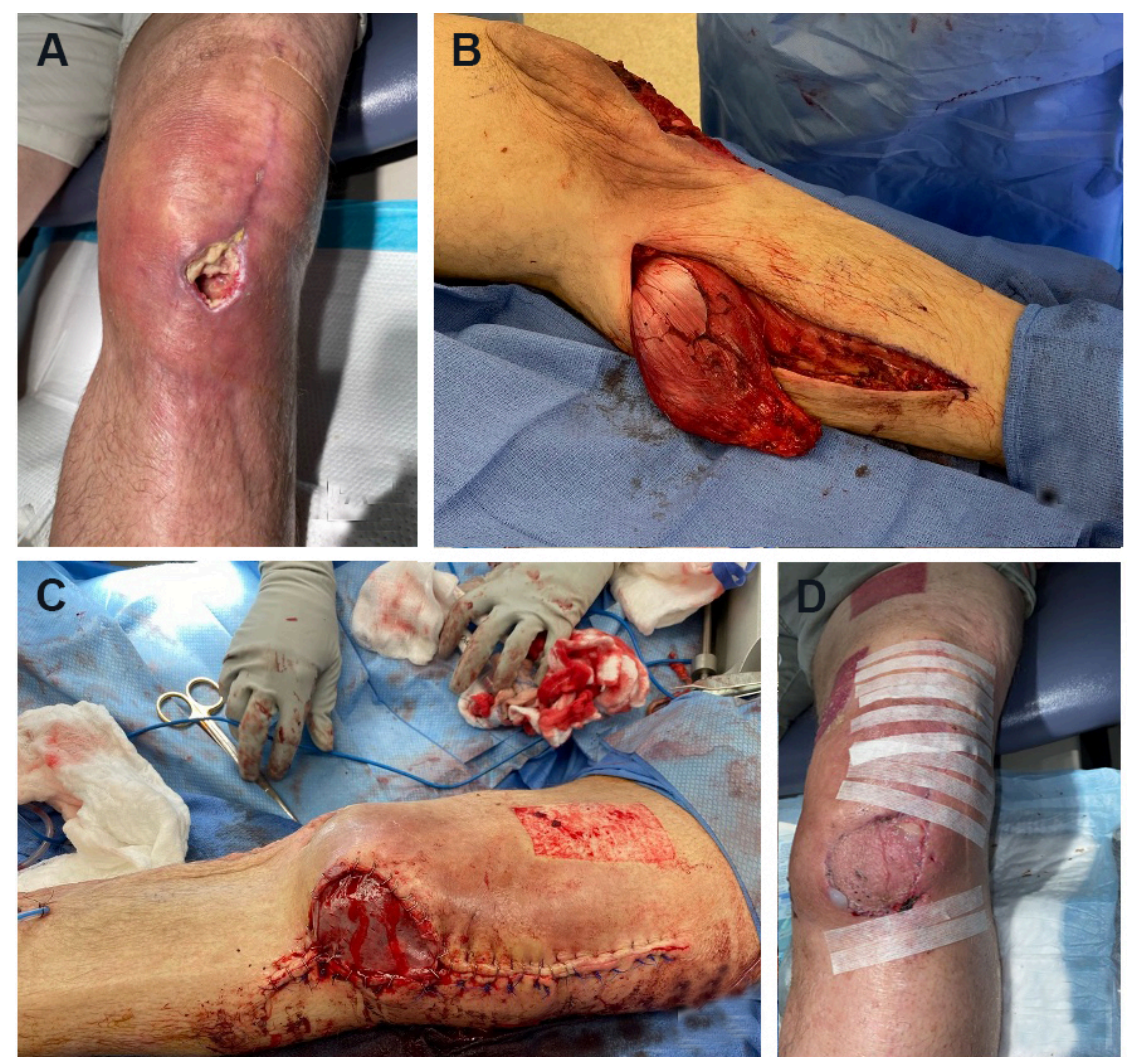

Figure 3. Gastrocnemius flap. (A) Preoperative photo of a diabetic male who was four weeks s/p total knee arthroplasty with dehiscence and drainage at the left knee incision. (B) The medial gastrocnemius flap was harvested and rotated to cover the knee defect. (C) Flap inset into the knee defect. A split-thickness skin graft (STSG) was harvested from the medial thigh and placed over the flap. (D) Four weeks after flap with STSG.
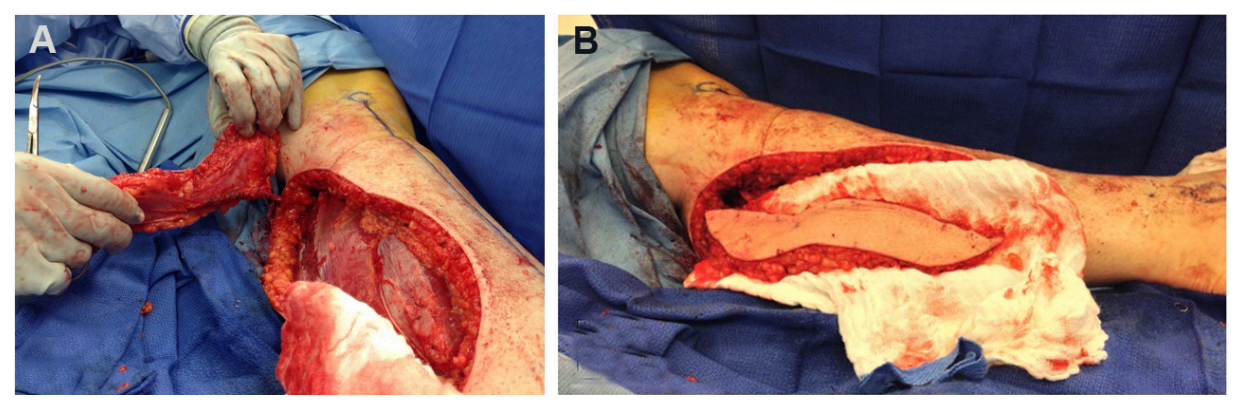

Figure 4. Medial sural artery perforator (MSAP) flap. (A) The MSAP flap spares the gastrocnemius muscle and can be used as a pedicled or free flap. (B) The MSAP flap dissected out.

larger caliber of tributaries ${ }^{[65,69]}$. The gracilis flap is another thigh-based option, but its short pedicle length often limits its usefulness [Figure 12].

Lastly, donor site morbidity is an important aspect to consider during free flap planning. Our group has found that donor site morbidity is lowest for ALT and VL flaps, especially when utilizing partial harvest of the VL tailored to the defect ${ }^{\left[{ }^{[}\right]}$. Alternatives such as the latissimus dorsi or free rectus flap are less preferred as they maintain upper body strength, should future amputation be necessary. Purnell et al. ${ }^{[70]}$ retrospectively reviewed 352 thigh-based flap donor sites and found similar donor site complications in 

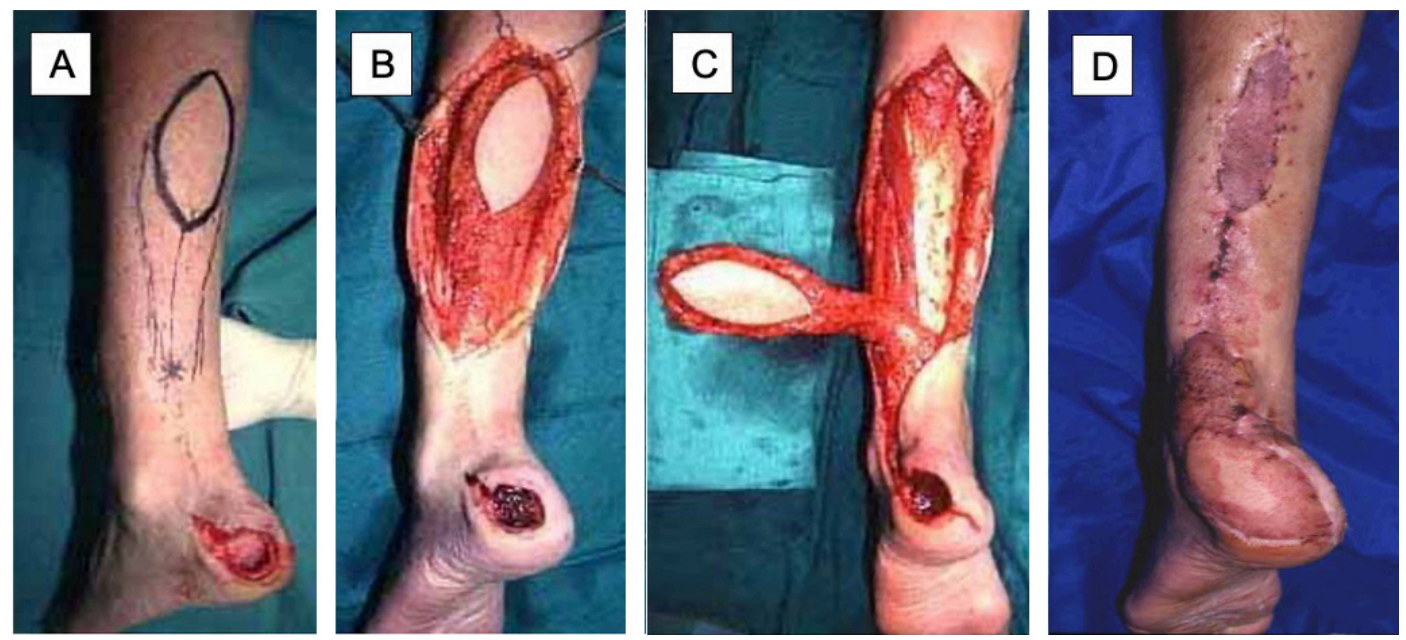

Figure 5. Reversed sural artery flap. (A) Initial presentation of calcaneal wound, flap was designed based on sural artery on posterior leg. (B) Dissection and elevation of the flap. (C) Rotation of the flap towards the calcaneal wound. (D) Healed flap; superior and inferior aspects of the donor site were covered with split-thickness skin graft, and the remainder was closed primarily.
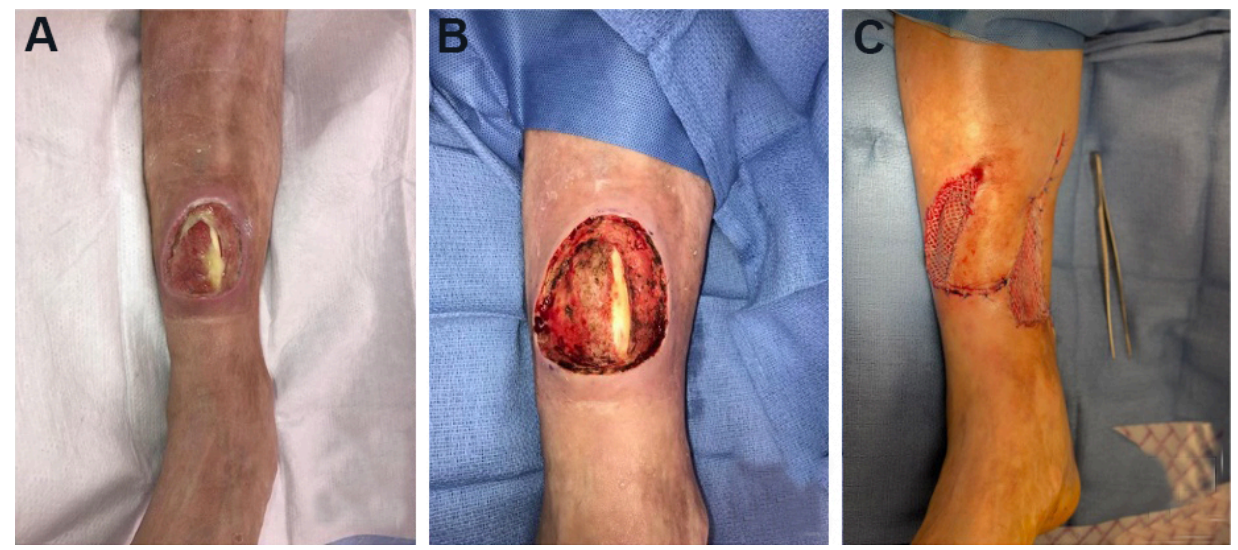

Figure 6. Saphenous artery perforator propeller flap. (A) Initial presentation of circular wound over distal anterior leg with exposed anterior tibial tendon. (B) Wound after excisional debridement. (C) Flap was inset, and a split-thickness skin graft was placed over the lateral portion of the wound where tendon was not exposed and the medial defect where the flap was harvested.

both lateral and medial thigh-based flap harvest. Furthermore, they suggested that the inclusion of muscle does not increase complications, but the inclusion of a skin paddle with gracilis muscle or skin grafted lateral thigh donor site resulted in increased wound healing complications ${ }^{[70]}$.

\section{Microvascular anastomotic techniques}

A reliable anastomotic technique during microsurgical reconstruction is vital for free flap success. Patients with LE wounds are often vasculopaths with fragile, fibrotic, and stenotic arteries. End-to-side (ETS) anastomosis is important in this patient population to preserve distal flow to the extremity [Figure 13]. Our preferred approach is a longitudinal slit arteriotomy ETS microvascular anastomosis ${ }^{[43]}$. ETS anastomosis ensures laminar flow and may even have higher flow rates than end-to-end anastomosis ${ }^{[3,7,7,72]}$. The longitudinal slit technique allows for minimal intimal disruption and controls vessel mismatch ${ }^{[4,71,73]}$. After flap harvest, a 70-degree bevel is created on the flap artery to obtain a final 20-degree resting angle. An ophthalmic blade can be used. The recipient vessel is examined carefully for an area of least calcification, and proximal and distal control is obtained. A single longitudinal straight-line incision is made to the length 

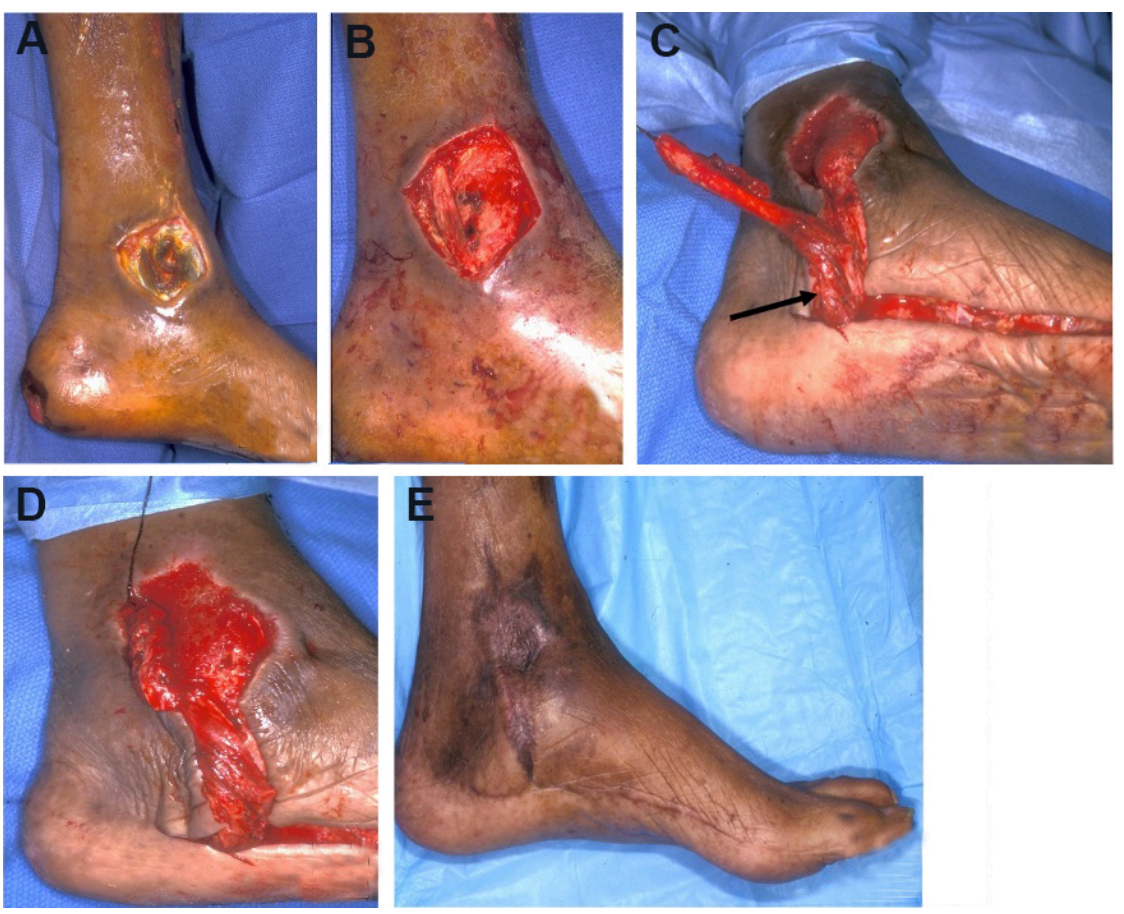

Figure 7. Abductor hallucis (AH) local flap. (A) Initial presentation of a medial ankle wound; depth is down to bone. (B) Wound after debridement. (C) After dissection of the AH muscle, it was released from its insertion point distally; arrow points to the dominant vascular pedicle (medial plantar artery). (D) Flap inset. (E) Results at follow-up. The skin graft and donor site incisions were wellhealed. The muscle flap provided adequate bulk over the bony heel defect.
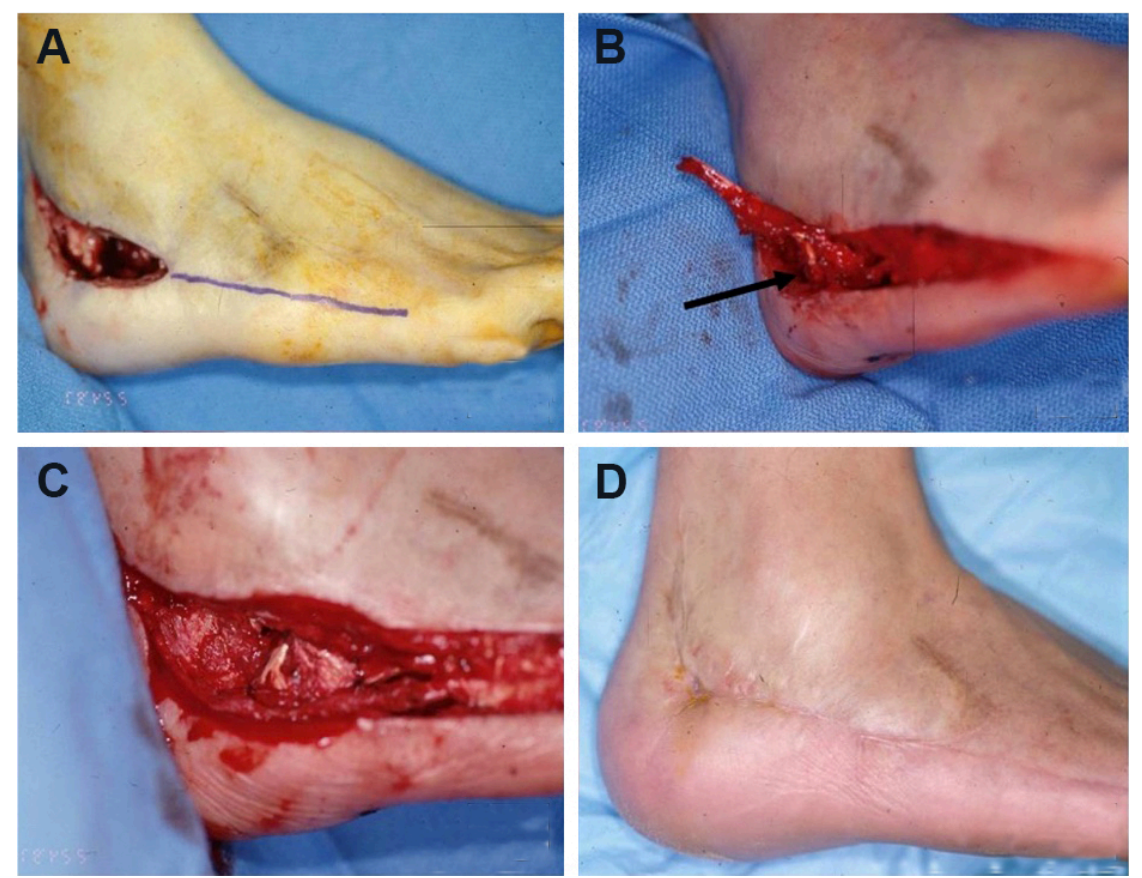

Figure 8. Abductor digiti minimi (ADM) local flap. (A) Initial presentation of osteomyelitis of the lateral calcaneus; purple line marks where incision was performed. (B) After dissection of the ADM muscle, it was released from its insertion point distally; arrow points to the dominant vascular pedicle (lateral plantar artery). (C) Flap inset. (D) The wound and donor site incisions were closed primarily and healed well. 

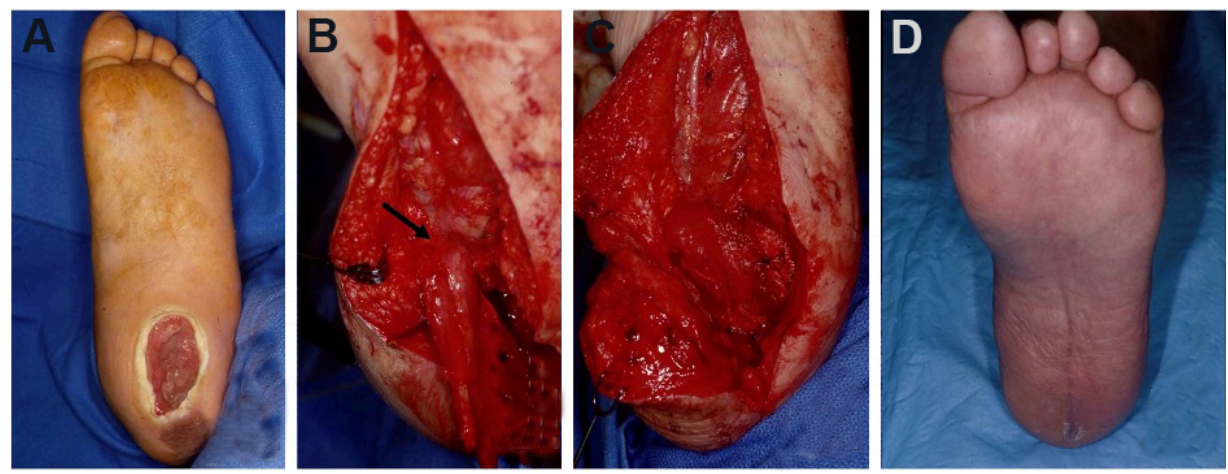

Figure 9. Flexor digitorum brevis (FDM) local flap. (A) Initial presentation of plantar wound. (B) Dissection of the FDM muscle; arrow points to the dominant vascular pedicle (lateral plantar artery). (C) Flap inset. (D) The wound and donor site incisions were closed primarily and healed well.
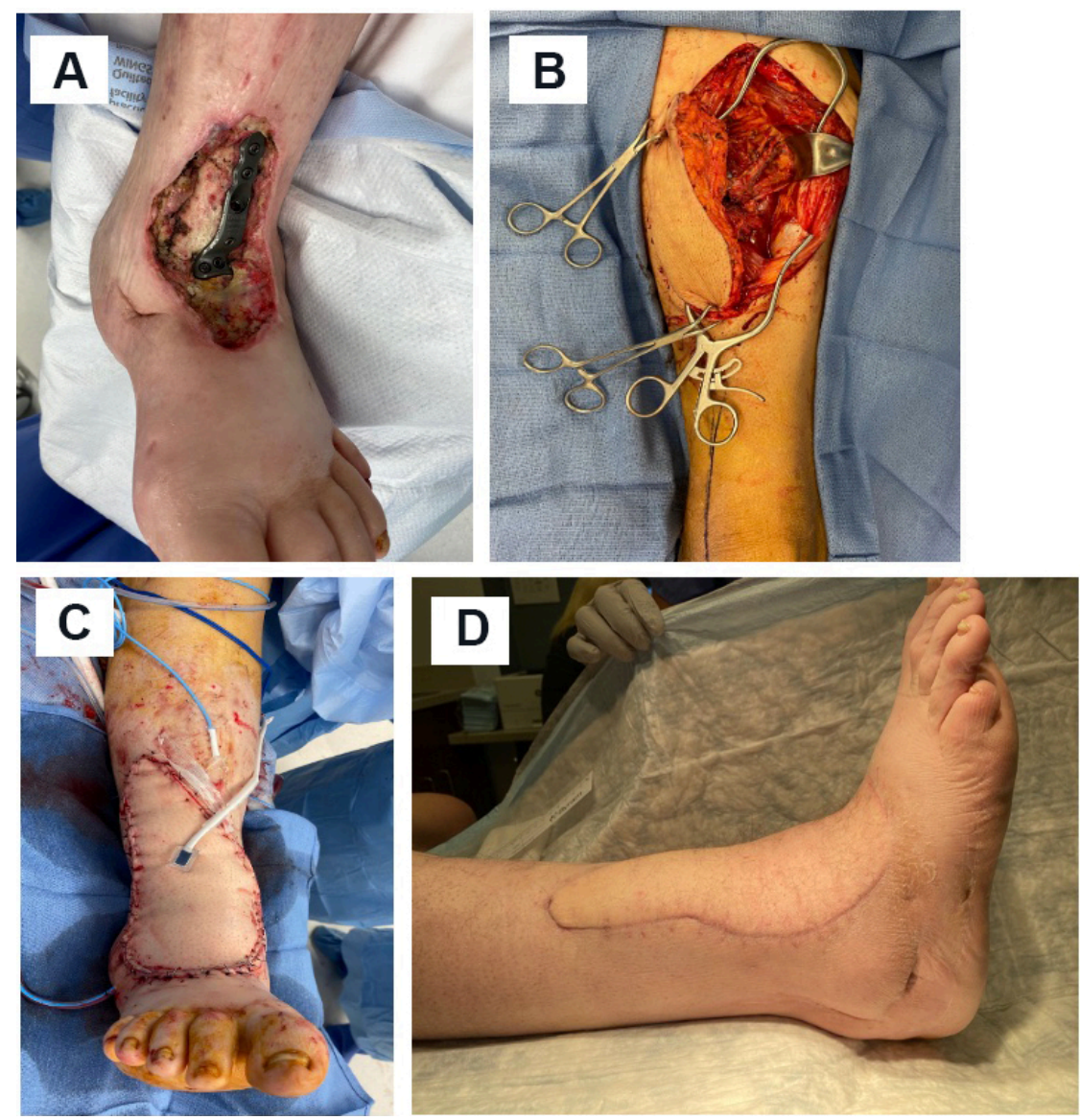

Figure 10. Anterolateral thigh (ALT) free flap. (A) large non-healing wound with exposed hardware and bone over anterior ankle. (B) Harvest of ALT flap from the ipsilateral thigh. (C) Flap inset over the wound. (D) Healed flap.

of the beveled flap artery. It is critical to make the slit arteriotomy in a smooth fashion to prevent intimal flap formation. The vessels are then hand-sewn ETS using 8-0 or 9-0 nylon suture from outside-to-inside fashion on the flap vessel and an inside-to-outside fashion on the recipient vessel to allow for intimal tacking. Our center showed $93 \%$ flap success and a limb salvage rate of $83.5 \%$ with longitudinal slit arteriotomy ETS anastomosis ${ }^{[43]}$. When feasible, dual venous anastomoses to the deep or superficial venous 

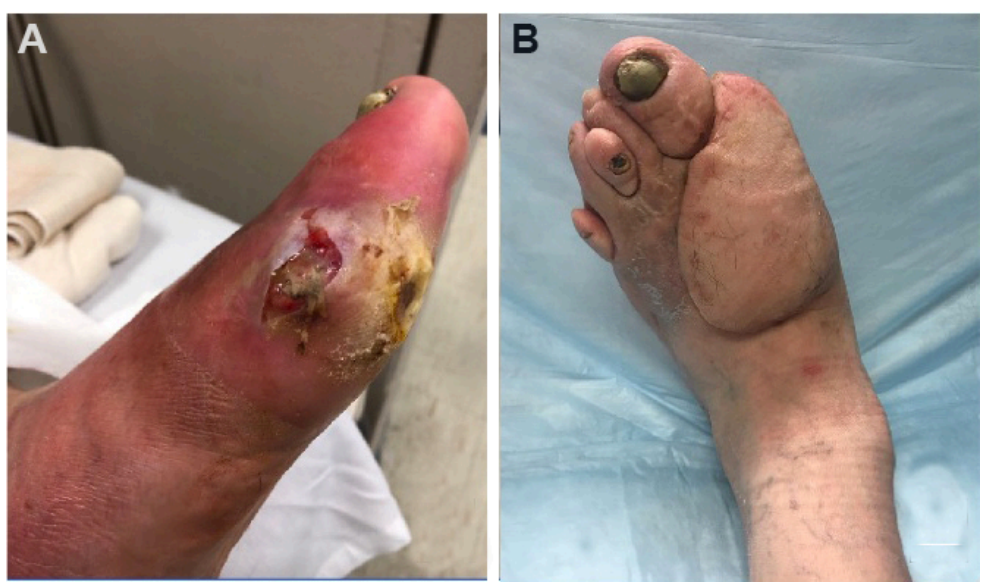

Figure 11. Superior circumflex iliac artery perforator (SCIP) free flap. (A) Diabetic foot ulcer of the left hallux with exposed first metatarsal joint. (B) Healed SCIP flap several months after surgery.
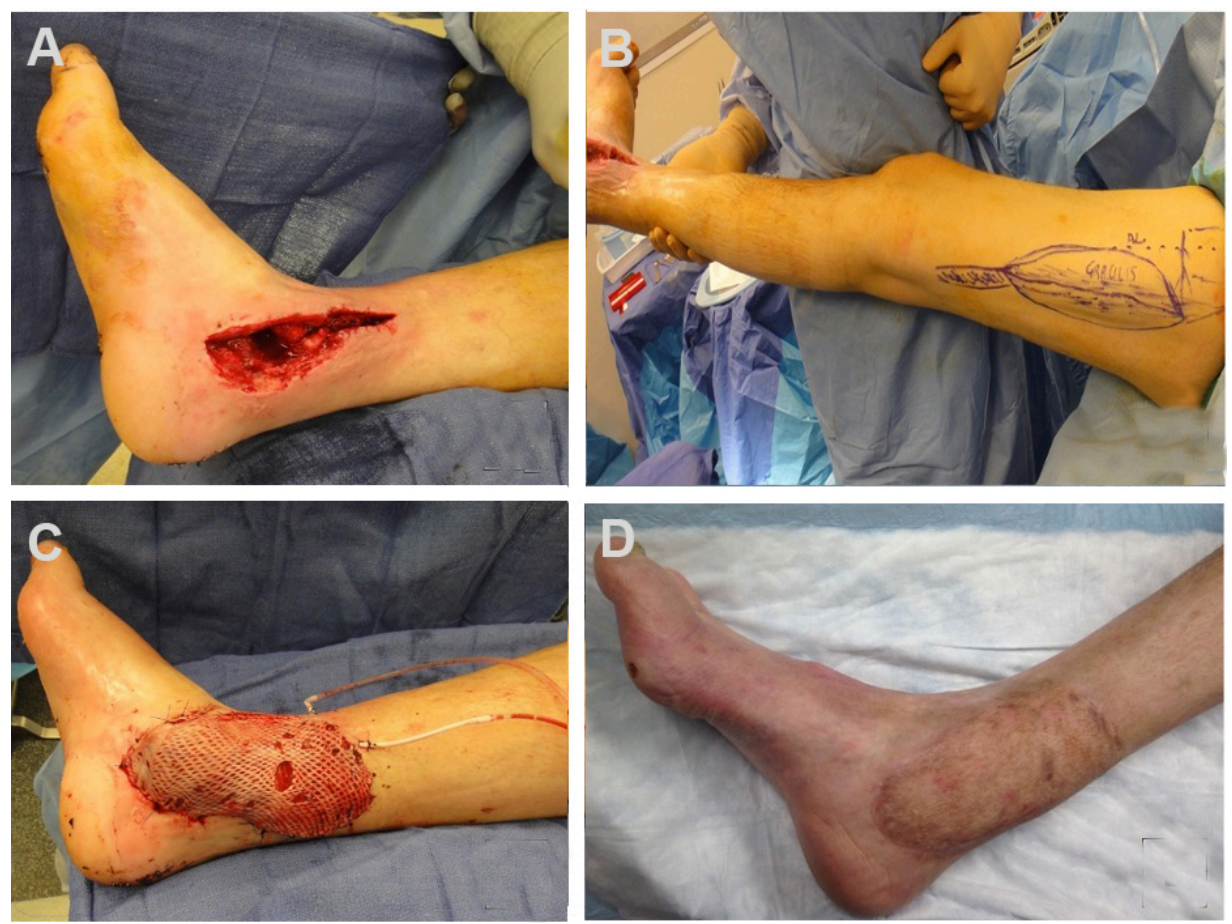

Figure 12. Gracilis free flap. (A) Initial presentation of medial ankle wound. (B) Gracilis free flap was marked out preoperatively. (C) Flap inset with an overlying split-thickness skin graft. (D) Healed flap one year after surgery.

system are performed with a GEM microvascular coupler (Synovis Micro Companies, Alliance, Inc., Birmingham, AL). In the absence of high-quality deep-system veins (i.e., pre-existing thrombosis, inadequate caliber, and/or scarring), the saphenous vein can be used. Intraoperatively, an implantable Cook Doppler probe (Cook Medical, Bloomington, IN) can be placed on the venous pedicle to monitor the patency of the anastomosis ${ }^{[74]}$.

Free flap LE reconstruction in comorbid patients

Many patients who present with chronic LE wounds have underlying comorbidities that affect their 

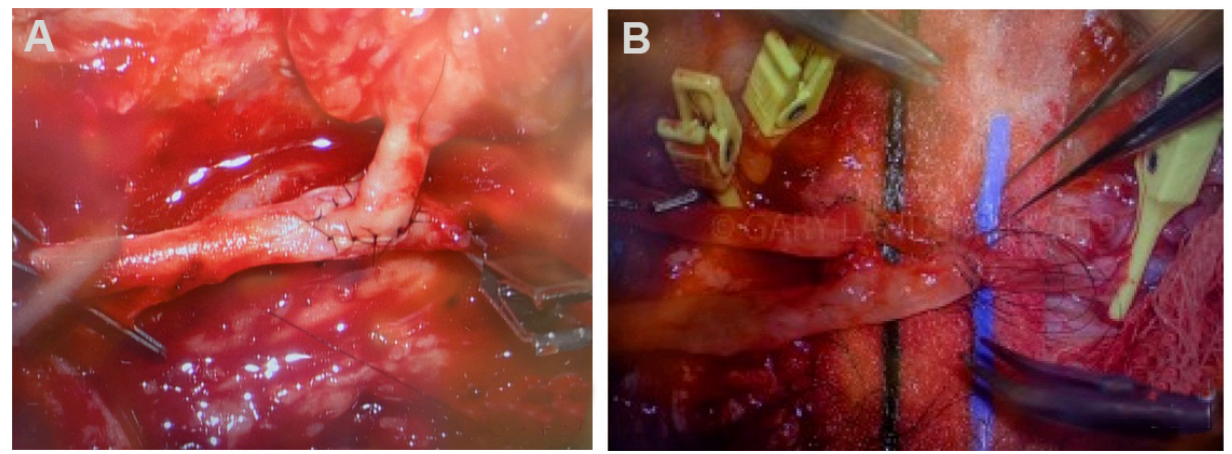

Figure 13. End-to-side arterial anastomosis. (A, B) end-to-side microvascular arterial anastomosis.

vasculature, such as DM and PVD. DM was previously regarded as a relative contraindication to LE free flap reconstruction; however, multiple studies have shown successful microvascular FTT in diabetic patient ${ }^{[5,10,63,75,76]}$. Nevertheless, these patients present a unique challenge for free flap reconstruction because the vessels available for anastomosis are often fragile, fibrotic, and stenotic as a result of infection, severe calcification, and comorbid atherosclerosis ${ }^{[50,77]}$. The calcified arteries increase the risk of intimal dissection during microsurgical anastomosis, which can lead to vessel thrombosis and other complications ${ }^{[78]}$.

Additionally, diabetic patients often have concomitant PVD, which may hinder the number of recipient vessels available for anastomosis. FTT should be considered for LE defects located in ischemic angiosome regions with minimal in-line blood flow. In these instances, performing ETS anastomosis during FTT can serve as a vascular bypass and provide "indirect extremity revascularization" ${ }^{[79]}$. In instances when both the flap and recipient arteries are calcified, the senior author (Evans KK) performs ETS saphenous interposition vein graft, which decreases the risk of intimal disruption ${ }^{[43,50,80]}$. Vascular instruments, such as Debakey or Satinsky clamps, are sometimes used to attain proximal and distal control in these vessels as the usual microvascular bulldog clamps are not strong enough to occlude the vessels if there is hardened calcium present. A specialized hardened cardiac needle is also needed to penetrate the calcium to perform microanastomosis [Figure 14].

\section{Postoperative flap care}

After minimal tension closure with nonabsorbable suture and staples, a nonadherent dressing is applied to the flap. A bulky padded dressing is applied to minimize pressure and shear on the flap. An external fixator can be applied for the purpose of postoperative offloading. All flaps should be carefully monitored after surgery. The flap should be routinely examined for color or temperature changes and signs of infection. Darkening of the flap may indicate venous congestion, whereas pale color or coolness to the touch may signal a decrease in arterial flow to the flap. A handheld Doppler is useful for examining possible arterial compromise. In the setting of free flaps, a high index of suspicion for possible flap compromise is critical, as a prompt surgical intervention to interrogate the anastomosis can salvage the flap. Hyperbaric oxygen therapy is a useful adjunct in settings of compromised flap vascularity. It is critical that patients remain nonweight bearing (NWB) on the operative limb. NWB is usually recommended for 4-6 weeks following surgery, and gradual weight bearing begins after the incisions have healed. Physical therapy is required to improve strength and conditioning.

\section{CONCLUSION}

Soft tissue reconstruction of LE defects should be centered on attaining optimal functional outcomes. Flap coverage is the reconstructive modality of choice for defects with exposed tendons, joints, or bones. Local 


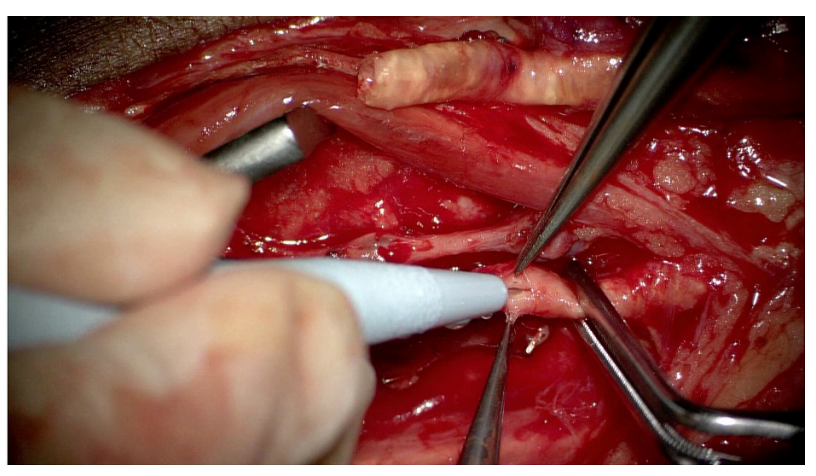

Figure 14. Calcified flap and recipient arteries. Calcified descending branch of the lateral circumflex artery (top of photo) and posterior tibial artery. Satinsky clamps were used to attain proximal and distal control on the artery. Calcifications are seen in the lumen of both arteries.

flaps are viable options for small defects that are within reach. Free flaps have become a mainstay in LE reconstruction with high rates of flap success and long-term limb salvage. Preoperative optimization, a multidisciplinary team approach, and adequate postoperative care are crucial. FTT reconstruction is not "one size fits all"; careful consideration of patient comorbidities, donor site morbidity, and functional and aesthetic outcome are of utmost importance when choosing flap type.

\section{DECLARATIONS}

\section{Authors' contributions}

Designed and wrote majority of the manuscript: Deldar R

Contributed to writing manuscript: Merle C

Edited the manuscript: Attinger CE

Provided main conceptual design of manuscript and edited the manuscript: Evans KK

\section{Availability of data and materials}

Not applicable.

\section{Financial support and sponsorship}

None.

\section{Conflicts of interest}

All authors declared that there are no conflicts of interest.

\section{Ethical approval and consent to participate}

The study was approved by institutional review board. IRB Study 0007611 entitled "MedStar Plastic Reconstructive Surgery Outcomes Registry" was approved by MedStar Health Research Institute.

\section{Consent for publication}

Not applicable.

\section{Copyright}

(c) The Author(s) 2022. 


\section{REFERENCES}

1. Agale SV. Chronic leg ulcers: epidemiology, aetiopathogenesis, and management. Ulcers 2013;2013:1-9. DOI

2. Järbrink K, Ni G, Sönnergren H, et al. Prevalence and incidence of chronic wounds and related complications: a protocol for a systematic review. Syst Rev 2016;5:152. DOI PubMed PMC

3. Mekkes JR, Loots MA, Van Der Wal AC, Bos JD. Causes, investigation and treatment of leg ulceration. Br J Dermatol 2003;148:388401. DOI PubMed

4. Chatterjee SS. Venous ulcers of the lower limb: where do we stand? Indian J Plast Surg 2012;45:266-74. DOI PubMed PMC

5. Lee ZH, Daar DA, Stranix JT, et al. Free-flap reconstruction for diabetic lower extremity limb salvage. J Surg Res 2020;248:165-70. DOI PubMed

6. Pecoraro RE, Reiber GE, Burgess EM. Pathways to diabetic limb amputation. Basis for prevention. Diabetes Care 1990;13:513-21. DOI PubMed

7. Narres M, Kvitkina T, Claessen H, et al. Incidence of lower extremity amputations in the diabetic compared with the non-diabetic population: a systematic review. PLoS One 2017;12:e182081. DOI PubMed PMC

8. Armstrong DG, Swerdlow MA, Armstrong AA, Conte MS, Padula WV, Bus SA. Five year mortality and direct costs of care for people with diabetic foot complications are comparable to cancer. $J$ Foot Ankle Res 2020;13:16. DOI PubMed PMC

9. Bekeny JC, Zolper EG, Steinberg JS, Attinger CE, Fan KL, Evans KK. Free tissue transfer for patients with chronic lower extremity wounds. Clin Plast Surg 2021;48:321-9. DOI PubMed

10. Ducic I, Attinger CE. Foot and ankle reconstruction: pedicled muscle flaps versus free flaps and the role of diabetes. Plast Reconstr Surg 2011;128:173-80. DOI PubMed

11. Ecker ML, Jacobs BS. Lower extremity amputation in diabetic patients. Diabetes 1970;19:189-95. DOI PubMed

12. Kucan JO, Robson MC. Diabetic foot infections: fate of the contralateral foot. Plast Reconstr Surg 1986;77:439-41. DOI PubMed

13. Endara M, Masden D, Goldstein J, Gondek S, Steinberg J, Attinger C. The role of chronic and perioperative glucose management in high-risk surgical closures: a case for tighter glycemic control. Plast Reconstr Surg 2013;132:996-1004. DOI PubMed

14. Bollig CA, Spradling CS, Dooley LM, Galloway TL, Jorgensen JB. Impact of perioperative hyperglycemia in patients undergoing microvascular reconstruction. Head Neck 2018;40:1196-206. DOI PubMed

15. Yu J, Hong JP, Suh HP, et al. Prognostic nutritional index is a predictor of free flap failure in extremity reconstruction. Nutrients 2020;12:562. DOI PubMed PMC

16. Stechmiller JK. Understanding the role of nutrition and wound healing. Nutr Clin Pract 2010;25:61-8. DOI PubMed

17. Margarson MP, Soni N. Serum albumin: touchstone or totem? Anaesthesia 1998;53:789-803. DOI PubMed

18. Kim KG, Mishu M, Zolper EG, et al. Nutritional markers for predicting lower extremity free tissue transfer outcomes in the chronic wound population. Microsurgery 2021. DOI PubMed

19. Shum J, Markiewicz MR, Park E, et al. Low prealbumin level is a risk factor for microvascular free flap failure. J Oral Maxillofac Surg 2014;72:169-77. DOI PubMed

20. Ehrl D, Heidekrueger PI, Haas EM, et al. Does cigarette smoking harm microsurgical free flap reconstruction? J Reconstr Microsurg 2018;34:492-8. DOI PubMed

21. Wang TY, Serletti JM, Cuker A, et al. Free tissue transfer in the hypercoagulable patient: a review of 58 flaps. Plast Reconstr Surg 2012;129:443-53. DOI PubMed

22. DeFazio MV, Economides JM, Anghel EL, Tefera EA, Evans KK. Lower extremity free tissue transfer in the setting of thrombophilia: analysis of perioperative anticoagulation protocols and predictors of flap failure. J Reconstr Microsurg 2019;35:270-86. DOI PubMed

23. DeFazio MV, Hung RW, Han KD, Bunting HA, Evans KK. Lower extremity flap salvage in thrombophilic patients: managing expectations in the setting of microvascular thrombosis. J Reconstr Microsurg 2016;32:431-44. DOI PubMed

24. Anghel EL, DeFazio MV, Barker JC, Janis JE, Attinger CE. Current concepts in debridement: science and strategies. Plast Reconstr Surg 2016;138:82S-93S. DOI PubMed

25. Siddiqui AR, Bernstein JM. Chronic wound infection: facts and controversies. Clin Dermatol 2010;28:519-26. DOI PubMed

26. Kotha VS, Fan KL, Schwitzer JA, et al. Amputation versus free flap: long-term outcomes of microsurgical limb salvage and risk factors for amputation in the diabetic population. Plast Reconstr Surg 2021;147:742-50. DOI PubMed

27. Kanuri A, O'Kelly ND, Shuck J, Kim P, Evans KK, Attinger CE. The effect of positive postdebridement cultures on local muscle flap reconstruction of the lower extremity. Plast Reconstr Surg Glob Open 2018;6:e1864. DOI PubMed PMC

28. Carroll AM, Kim KG, Walters ET, et al. Glove and instrument changing to prevent bacterial contamination in infected wound debridement and closure procedures: a prospective observational study. Int Wound J 2021;18:664-9. DOI PubMed PMC

29. Reiber GE, Vileikyte L, Boyko EJ, et al. Causal pathways for incident lower-extremity ulcers in patients with diabetes from two settings. Diabetes Care 1999;22:157-62. DOI PubMed

30. Boyko EJ, Ahroni JH, Stensel V, Forsberg RC, Davignon DR, Smith DG. A prospective study of risk factors for diabetic foot ulcer. The Seattle Diabetic Foot Study. Diabetes Care 1999;22:1036-42. DOI PubMed

31. Fernando M, Crowther R, Lazzarini P, et al. Biomechanical characteristics of peripheral diabetic neuropathy: a systematic review and meta-analysis of findings from the gait cycle, muscle activity and dynamic barefoot plantar pressure. Clin Biomech (Bristol, Avon) 2013;28:831-45. DOI PubMed

32. Shenoy AM. Guidelines in practice: treatment of painful diabetic neuropathy. Continuum (Minneap Minn) 2012;18:192-8. DOI PubMed

33. Andersen H. Motor dysfunction in diabetes. Diabetes Metab Res Rev 2012;28 Suppl 1:89-92. DOI PubMed 
34. Nishimoto GS, Attinger CE, Cooper PS. Lengthening the Achilles tendon for the treatment of diabetic plantar forefoot ulceration. Surg Clin North Am 2003;83:707-26. DOI PubMed

35. Armstrong DG, Stacpoole-Shea S, Nguyen H, Harkless LB. Lengthening of the Achilles tendon in diabetic patients who are at high risk for ulceration of the foot. J Bone Joint Surg Am 1999;81:535-8. DOI PubMed

36. Lin SS, Lee TH, Wapner KL. Plantar forefoot ulceration with equinus deformity of the ankle in diabetic patients: the effect of tendoAchilles lengthening and total contact casting. Orthopedics 1996;19:465-75. PubMed

37. Lavery LA, Armstrong DG, Boulton AJ; Diabetex Research Group. Ankle equinus deformity and its relationship to high plantar pressure in a large population with diabetes mellitus. J Am Podiatr Med Assoc 2002;92:479-82. DOI PubMed

38. Colen LB, Kim CJ, Grant WP, Yeh JT, Hind B. Achilles tendon lengthening: friend or foe in the diabetic foot? Plast Reconstr Surg 2013;131:37e-43e. DOI PubMed

39. Segal LS, Thomas SE, Mazur JM, Mauterer M. Calcaneal gait in spastic diplegia after heel cord lengthening: a study with gait analysis. J Pediatr Orthop 1989;9:697-701. DOI PubMed

40. Sponer P, Kucera T, Brtková J, Srot J. The management of Charcot midfoot deformities in diabetic patients. Acta Medica (Hradec Kralove) 2013;56:3-8. DOI PubMed

41. Janhofer DE, Lakhiani C, Kim PJ, et al. The utility of preoperative arteriography for free flap planning in patients with chronic lower extremity wounds. Plast Reconstr Surg 2019;143:604-13. DOI PubMed

42. Ziegler-Graham K, MacKenzie EJ, Ephraim PL, Travison TG, Brookmeyer R. Estimating the prevalence of limb loss in the United States: 2005 to 2050. Arch Phys Med Rehabil 2008;89:422-9. DOI PubMed

43. Black C, Fan KL, Defazio MV, et al. Limb salvage rates and functional outcomes using a longitudinal slit arteriotomy end-to-side anastomosis for limb-threatening defects in a high-risk patient population. Plast Reconstr Surg 2020;145:1302-12. DOI PubMed

44. Cavanagh PR, Lipsky BA, Bradbury AW, Botek G. Treatment for diabetic foot ulcers. Lancet 2005;366:1725-35. DOI PubMed

45. Basheer MH, Wilson SM, Lewis H, Herbert K. Microvascular free tissue transfer in reconstruction of the lower limb. J Plast Reconstr Aesthet Surg 2008;61:525-8. DOI PubMed

46. Janhofer DE, Lakhiani C, Kim PJ, et al. The utility of preoperative venous testing for lower extremity flap planning in patients with lower extremity wounds. Plast Reconstr Surg 2020;145:164e-71e. DOI PubMed

47. Fischer JP, Wink JD, Nelson JA, et al. A retrospective review of outcomes and flap selection in free tissue transfers for complex lower extremity reconstruction. J Reconstr Microsurg 2013;29:407-16. DOI PubMed

48. Taylor G, Palmer J. The vascular territories (angiosomes) of the body: experimental study and clinical applications. Br J Plast Surg 1987;40:113-41. DOI PubMed

49. Attinger CE, Evans KK, Bulan E, Blume P, Cooper P. Angiosomes of the foot and ankle and clinical implications for limb salvage: reconstruction, incisions, and revascularization. Plast Reconstr Surg 2006;117:261S-93S. DOI PubMed

50. Black CK, Kotha VS, Fan KL, Ragothaman K, Attinger CE, Evans KK. Pedicled and free tissue transfers. Clin Podiatr Med Surg 2019;36:441-55. DOI PubMed

51. Shishehbor MH. Acute and critical limb ischemia: when time is limb. Cleve Clin J Med 2014;81:209-16. DOI PubMed

52. Attinger C, Cooper P, Blume P. Vascular anatomy of the foot and ankle. Operative Techniques in Plastic and Reconstructive Surgery 1997;4:183-98. DOI

53. Taylor GI, Pan WR. Angiosomes of the leg: anatomic study and clinical implications. Plast Reconstr Surg 1998;102:599-616; discussion 617-8. PubMed

54. Bareither D. Sarrafian's Anatomy of the foot and ankle. J Am Podiatr Med Assoc 2012;102:350-350. DOI

55. Attinger CE, Ducic I, Cooper P, Zelen CM. The role of intrinsic muscle flaps of the foot for bone coverage in foot and ankle defects in diabetic and nondiabetic patients. Plast Reconstr Surg 2002;110:1047-54; discussion 1055-7. DOI PubMed

56. AlMugaren FM, Pak CJ, Suh HP, Hong JP. Best local flaps for lower extremity reconstruction. Plast Reconstr Surg Glob Open 2020;8:e2774. DOI PubMed PMC

57. Hong J, Hallock G. Lower extremity reconstruction: a practical guide. Thieme 2021. DOI

58. El-Shazly M, Kamal A. Practical guidelines for getting the most out of the gastrocnemius muscle flap units: a presented algorithm for the best flap choice. Eur J Plast Surg 2012;35:589-94. DOI

59. Al-Himdani S, Din A, Wright TC, Wheble G, Chapman TWL, Khan U. The medial sural artery perforator (MSAP) flap: a versatile flap for lower extremity reconstruction. Injury 2020;51:1077-85. DOI PubMed

60. Ciofu RN, Zamfirescu DG, Popescu SA, Lascar I. Reverse sural flap for ankle and heel soft tissues reconstruction. J Med Life 2017;10:94-8. PubMed PMC

61. Mehrotra S. Perforator-plus flaps: a new concept in traditional flap design. Plast Reconstr Surg 2007;119:590-8. DOI PubMed

62. Song P, Pu LLQ. Perforator-plus flaps in lower extremity reconstruction. Clin Plast Surg 2021;48:183-92. DOI PubMed

63. Sato T, Yana Y, Ichioka S. Free flap reconstruction for diabetic foot limb salvage. J Plast Surg Hand Surg 2017;51:399-404. DOI PubMed

64. Lu J, DeFazio MV, Lakhiani C, et al. Limb salvage and functional outcomes following free tissue transfer for the treatment of recalcitrant diabetic foot ulcers. J Reconstr Microsurg 2019;35:117-23. DOI PubMed

65. Hong JP. The superficial circumflex iliac artery perforator flap in lower extremity reconstruction. Clin Plast Surg 2021;48:225-33. DOI PubMed

66. Basci D, Gosman A. Basics of flaps. In: Janis JE, editor. Essentials of plastic surgery. CRC Press; 2014. DOI

67. Hollenbeck ST, Woo S, Komatsu I, Erdmann D, Zenn MR, Levin LS. Longitudinal outcomes and application of the subunit principle to 165 foot and ankle free tissue transfers. Plast Reconstr Surg 2010;125:924-34. DOI PubMed 
68. Hanasono MM, Skoracki RJ, Yu P. A prospective study of donor-site morbidity after anterolateral thigh fasciocutaneous and myocutaneous free flap harvest in 220 patients. Plast Reconstr Surg 2010;125:209-14. DOI PubMed

69. Koshima I, Nanba Y, Tsutsui T, et al. Superficial circumflex iliac artery perforator flap for reconstruction of limb defects. Plast Reconstr Surg 2004;113:233-40. DOI PubMed

70. Purnell CA, Lewis KC, Mioton LM, et al. Donor-site morbidity of medial and lateral thigh-based flaps: a comparative study. Plast Reconstr Surg Glob Open 2016;4:e1012. DOI PubMed PMC

71. Godina M. Preferential use of end-to-side arterial anastomoses in free flap transfers. Plast Reconstr Surg 1979;64:673-82. PubMed

72. Ikuta Y, Watari S, Kawamura K, et al. Free flap transfers by end-to-side arterial anastomosis. Br J Plast Surg 1975;28:1-7. DOI PubMed

73. Tan BK, Wong CH, Chew W, Hong SW. Use of the slit arteriotomy for end-to-side arterial anastomosis in free-tissue transfers to the extremities. J Plast Reconstr Aesthet Surg 2009;62:1519-23. DOI PubMed

74. Fan KL, Patel KM, Mardini S, Attinger C, Levin LS, Evans KK. Evidence to support controversy in microsurgery. Plast Reconstr Surg 2015;135:595e-608e. DOI PubMed

75. Fitzgerald O'Connor EJ, Vesely M, Holt PJ, Jones KG, Thompson MM, Hinchliffe RJ. A systematic review of free tissue transfer in the management of non-traumatic lower extremity wounds in patients with diabetes. Eur J Vasc Endovasc Surg 2011;41:391-9. DOI PubMed

76. Oh TS, Lee HS, Hong JP. Diabetic foot reconstruction using free flaps increases 5-year-survival rate. J Plast Reconstr Aesthet Surg 2013;66:243-50. DOI PubMed

77. Verhelle NA, Heymans O. How to deal with difficult microsurgical end-to-side anastomoses. Microsurgery 2005;25:203-8. DOI PubMed

78. Rifaï S, Boudard J, Haïun M, Obert L, Pauchot J. Tips and tricks for end-to-side anastomosis arteriotomies. Hand Surg Rehabil 2016;35:85-94. DOI PubMed

79. Shestak KC, Hendricks DL, Webster MW. Indirect revascularization of the lower extremity by means of microvascular free-muscle flap--a preliminary report. J Vasc Surg 1990;12:581-5. DOI PubMed

80. DeFazio MV, Fan KL, Evans KK. Greater saphenous vein-patch interposition to facilitate flow-sparing microanastomosis of calcified arteries in the distal lower extremity. Plast Reconstr Surg 2019;144:340e-1e. DOI PubMed 